\title{
LUGAR DE ALUNO É NA ESCOLA QUE DESENVOLVA CONHECIMENTOS
}

\author{
Janaína Moreira Pacheco de Souza 109 \\ Luiz Antonio Gomes Sennal10
}

\section{RESUMO}

O objetivo do presente estudo, de cunho bibliográfico, é suscitar algumas reflexões acerca da proposta de universalização escolar no contexto atual do nosso país. Para iniciarmos a discussão, traremos considerações de filósofos iluministas que pensaram a educação com uma visão voltada à cidadania. Na atualidade, um dos grandes discursos direcionados à área da educação é a promoção da equidade de ensino. Com o objetivo de compreender o papel que a escola e o professor exercem nesse processo, garantindo acesso e permanência do aluno na escola, abordaremos questões relacionadas ao processo de construção do conhecimento que permeia tanto quem ensina, quanto quem aprende. A ideia defendida no corpo do texto será a de que o processo de universalização escolar só se efetivará mediante reflexões que envolvam todas as instâncias de ensino; apropriação pelo professor da sua real função no processo educativo e, valorização da educação por parte do Estado. Para embasarmos tal posição, traremos estudos de Senna (1997, 2008), Becker (1993), Berticelli (2004) e Libâneo (2012, 2013) que apontam possibilidades pedagógicas reais e ideias no/para o cotidiano escolar que permitam ao indivíduo se desenvolver enquanto cidadão.

Palavras-chave: Cidadania. Conhecimento. Escola.

\section{STUDENTS DESERVE A SCHOOL THAT DEVELOPS SKILLS}

\begin{abstract}
This bibliographic survey arises reflections about Brazilian contemporary efforts towards the universal access to school. As a base for discussion we bring about the contributions of some Illuminist philosophers which used Education as a tool for citizenship, what still remains in today's educational discourses, concerned with the promotion of learning equity. Aiming to analyze the role of school and its teachers exert in this process - granting students to access and remain in school - in the sequence of this paper, the reader will find some questions related to the process of knowledge construction, which permeates both, those who teach, and those who
\end{abstract}

109 Doutoranda em Educação pela Universidade Estadual do Rio de Janeiro (UERJ). Docente de Língua Portuguesa no Colégio Brigadeiro Newton Braga - RJ (FAB). E-mail: janwan91@ig.com.br

110 Doutor em Linguística Aplicada (PUC-Rio). Docente do Programa de Pós-graduação em Educação da Universidade do Estado do Rio de Janeiro (UERJ).E-mail: senna@senna.pro.br

Revista Exitus, Santarém/PA, Vol. 7, № 1, p. 269-288, Jan/Abr 2017. 
learn. The central idea defended here is that the process of school universalization depends on discussions involving all instances of the teaching process, followed by the assimilation by teachers regarding their real roles in school education and, at least, the enhancement of Education into official policies and governor targets. Conceptual references from: Senna (2007; 2008), Becjer (1993), Berticelli (2004) and Libaneo $(2012 ; 2013)$, indicate that the pedagogic alternatives - real or ideal, into/for school routines - are the ones that ensure the development of citizenship.

Keywords: Citizenship. Knowledge. School.

\section{INTRODUÇÃO}

Nessas últimas duas décadas, segundo dados da Unesco (2015), o Brasil apresentou grandes avanços com relação à educação. A obrigatoriedade da matrícula das crianças de quatro a cinco anos na préescola, o acesso ao ensino fundamental quase universalizado, aumento no financiamento da educação e a promulgação do Plano Nacional fizeram com que nosso país tivesse certa credibilidade perante órgãos internacionais. Todavia, ainda nos falta muito.

Argumentar sobre o que ainda nos falta para podermos alcançar metas de desenvolvimento será uma tarefa improvável para um estudo dessa natureza, por isso, nos deteremos na discussão de alguns aspectos que consideramos importantes para promoção da equidade na educação brasileira.

O acesso dos alunos em nossas escolas públicas é uma situação quase resolvida. São pouquíssimas situações que persistem nessa problemática que nos afetou por tantos anos. Porém, o acesso por si só não basta. Junto a ele deve caminhar a permanência do aluno nas salas de aula e, para se promover isso, precisamos oferecer qualidade de ensino.

A equidade e a qualidade da educação são temas centrais na agenda da Unesco a partir de 2015. Investir de modo inteligente em professores e em outras reformas educacionais, visando ao fortalecimento igualitário da aprendizagem para transformar a longo prazo as prospecções das pessoas e das sociedades é meta pontual daqueles que se preocupam com a Educação (UNESCO, 2015). 
Nesse sentido, parece ser de fundamental importância, trazermos a esse estudo discussões que fomentem reflexões sobre o ensino que o Brasil oferece. Será que universalizar a educação basta? Como assegurar o desenvolvimento de um país sem a devida qualidade de ensino? Como promover equidade sem oferecer condições de aprendizagem? E nossos professores, será que estão preparados para atuarem nesse contexto que necessita de mudança? Qual o papel da escola - acolher ou incluir, transmitir ou desenvolver conhecimento?

No intuito de contribuir para essas reflexões, este trabalho de natureza bibliográfica tem como propósito percorrer os seguintes caminhos: demonstrar que o pensamento filosófico iluminista preconizava a universalização do ensino como desejo de transformação e aprendizagem (BOTO, 1996; CALÇA, 2010); refletir sobre o papel da escola e do professor como promotores do conhecimento científico e cultural dos alunos (MORRIN, 1999; SENNA, 2008; NÓVOA, 2009; RIBEIRO, 2011); e, ressaltar a importância da educação como forma de promover a equidade num país marcado pela desigualdade (BECKER, 1993; TARDIF, 2002 e LIBÂNEO, 2013).

\section{ALGUMAS CONTRIBUIÇÕES ILUMINISTAS PARA A EDUCAÇÃO}

A partir de meados do século XVIII, novos olhares voltaram-se à educação. A intensificação do pensamento pedagógico e a preocupação com a atitude educativa adquirem perspectivas totalizadoras e proféticas, tendendo a pontuar as estratégias pedagógicas como essenciais na transformação do ato de aprender. Segundo Boto (1996, p.23), "Advogar ou não a escola para todos foi, desde logo, estratégia política de matriz iluminista".

Os ideais dessa época trouxeram para a escola um status de instituição oficial, que teve como principais características sua independência religiosa e seu caráter universal de igualdade para todos. Essas contribuições permitiram uma maior racionalização do homem, 
enaltecendo a liberdade e a dignidade como parte da formação humana. É o surgimento da escola para a cidadania (BOTO, 1996).

Segundo Aranha (1989), Rousseau foi um dos filósofos que procurou, a partir de sua obra, criticar a educação de seu tempo e os preceitos propagados pela sociedade, os quais tinham bases constituídas no cerceamento da liberdade de expressão e pensamentos dos indivíduos. Além disso, corroborou com o intenso papel ocupado pelo ato de educar no imaginário social do Século das Luzes. Uma das propostas de Rousseau foi nortear a pedagogia como sinônimo de uma ação continuada com vistas ao estímulo e amor pelo conhecimento. "Não se trata mais de ensinar-lhe a ciência, mas de dar-lhe o gosto para amá-las e os métodos para aprendêlas, quando esse gosto estiver essencialmente desenvolvido. Esse é com certeza o princípio fundamental da boa educação" (1971, p.120).

Boto (1996) cita que Diderot pensava a aquisição de conhecimento como uma forma de reflexão, fazendo com que os indivíduos se desviassem de sua conformação social, trazendo-lhes esperanças e desejos inusitados de transformação. Diz ainda que ele defendia a ideia de estudos diversificados de acordo com a origem social do estudante.

\begin{abstract}
A instrução obrigatória constitui uma possibilidade única de fazer que todas as crianças, seja qual for sua origem, viva do mesmo modo e, nesse sentido, formem uma comunidade ainda que por alguns anos - com a condição de que as distinções de classe e de fortuna não se prolonguem mais oficialmente no interior do colégio, como era o caso do século XVII: nenhum aluno terá um quarto separado, um criado ou preceptor a serviço exclusivo de sua pessoa: que eles sejam todos confundidos, que eles aprendam a igualdade (DIDEROT, apud BOTO, 1996, p.57).
\end{abstract}

Observa-se que esse argumento proposto por Diderot, apesar de ser proferido há bastante tempo, permanece atual como possibilidade de atenuar desigualdades presentes em países como o nosso. Nesse contexto, a escola é apresentada como instrumento de transformação social e de equidade, possibilitando a todos os alunos, independentemente de sua origem, ter acesso à educação. 
A ideia da universalização educacional proposta pelo iluminismo já apresentava a "educação como o maior dos bens que o país pode legar a seus filhos, já que, ao contrário dos demais, ela não se dissipará" (ВОTO, 1996, p.55). A universalização do processo pedagógico era vista como sinônimo de engrandecimento da/para a nação. O dever maior do Estado era com a formação humana, tendo como objetivos principais a civilidade e a virtude.

É evidente que não existe nenhum tipo de cidadão no Estado para o qual não possa haver um tipo de educação que the seja própria; educação para os filhos de soberanos, educação para os filhos dos grandes, para os dos magistrados; educação para as crianças do campo ou, assim como existem escolas para aprender as verdades da religião, deverá haver também aquelas onde serão ensinados os exercícios, as práticas, os deveres e as virtudes do Estado, a fim de que se possa nele agir com maior conhecimento (ENCYCLOPEDIE, s.d., v.3, p.73, apud BOTO, 1996, p.56).

A arte de ensinar surge nos preceitos iluministas tendo como métodos o diálogo e a troca de experiências. O professor, que inicialmente era denominado 'preceptor', deveria se encarregar de instruir e formar a criança com a qual ele se instala na casa paterna. Cabia a ele escutar a fala dos discípulos, abrindo caminhos para o diálogo. Segundo os termos da Enciclopédia, o preceptor não deveria cobrar da criança apenas os termos da lição, mas utilizar o recurso do diálogo para dar sentido e substância à aprendizagem fazendo com que ele possa julgar o proveito que terá, não mediante o testemunho da memória, mas da vida (BOTO, 1996).

O reconhecimento e a valorização do professor como profissional é apontado por Calça (2010, p. 184) ao afirmar que Rousseau não concebia essa atividade como uma função missionária, mas como "um profissional que deve receber do Estado a segurança de uma espécie de aposentadoria, [...] uma espécie de carreira, a ser galgada através dos méritos e dedicação individuais".

Calça (2010) aponta em seus estudos que Rousseau já pensava a educação pública como possivel solução para os problemas que, porventura, surgissem. Para o filósofo a educação pública serviria mais como 
vacina que remédio, uma vez que reverter qualquer processo de perversão moral dará muito mais trabalho que educar.

Vimos através desses breves apontamentos que esse movimento intelectual procurou analisar a sociedade e suas instituições à luz da razão, fazendo com que se originasse um Estado preocupado com algumas questões educacionais. A universalidade, equidade, o ensino como desejo de transformação e a aprendizagem com o propósito de educar para a vida foram alguns projetos para a escola pública pautados no pensamento filosófico de alguns autores iluministas, os quais perduram até os dias atuais nas discussões ligadas à educação. Para tanto, observa-se que o movimento iluminista influenciou a educação contemporânea ao pensá-la através de uma visão voltada à cidadania.

\section{A ESCOLA COMO PRODUTORA DE CONHECIMENTO}

A escola pública moderna tem frutos de algumas heranças iluministas, as quais foram reinventadas, tendo em vista outro contexto sóciopolítico. Algumas visões levantadas pelos filósofos do século XVIII ainda perduram e continuam atuais em nossas mentes, transformando-se em questionamentos, tais como: a quem a escola se destinaria? Que finalidades teria? O que deveria promover? O que pretende superar (através de que meios e estratégias)?

De acordo com Severino (1984), apesar das heranças, estamos vivendo hoje um mundo totalmente diferente daquele projetado pela visão iluminista da modernidade. A revolução tecnológica se instalou em nossos dias, transmitindo informações de forma desmedida e incontida. O processo de globalização, não só da cultura, mas também da economia e da política fez com que tivéssemos que nos modificar para acompanhar as transformações de um mundo marcado pelo controle da iniciativa privada e pela ingerência do Estado. 
Estamos inseridos numa era em que a transmissão de informações não é mais privilégio da escola, como acontecia há algum tempo. Agora as certezas de que ela se dispunha, já não podem ser as mesmas de alguns anos. Nesse contexto, não cabe ao professor apenas a transmissão dos conteúdos programáticos, como originariamente era feito. Ele precisa possuir requisitos para conduzir esse processo, que a cada dia tem se tornado mais complexo. O educador precisa ser capaz de articular o conhecimento adquirido com a realidade de mundo, a fim de efetivar a capacidade do pensamento.

A imagem fictícia que se criou de escola como sistema estável, e que ainda muitos propagam, não condiz com a realidade instaurada em nosso país. Nossas instituições são marcadas por pessoas que vivem na instabilidade, que têm diferentes tipos sociais, com desejos e capacidades diversas. Em uma mesma sala de aula, convivemos com sujeitos que possuem as mais variadas características e, mesmo assim, teimamos em homogeneizá-los.

Pensar numa proposta de educação contemporânea para o Brasil é necessariamente ter que refletir sobre o conceito de diversidade, tendo em mente a coexistência singular do "mesmo" e do "outro" no espaço educacional, lançando mão de verdades que nos foram impostas durante séculos.

Atualmente a educação sinaliza para uma ação complexa do pensamento humano (MORRIN, 1999; RIBEIRO, 2011; SENNA, 2008), em que, a ideia de escola, aluno e aprendizagem não podem ser compreendidas como estáveis e universais.

Ribeiro (2011, apud FOUCAULT 1999, p.450) explica que o pensamento reflexivo deve se constituir como uma das formas de função articuladora para alcançarmos produção de conhecimento.

O homem não pôde desenhar-se como uma configuração na epistème, sem que o pensamento simultaneamente descobrisse, ao mesmo tempo em si e fora de si, nas suas margens, mas igualmente 
entrecruzados com sua própria trama, uma parte da noite, [...] um impensado que ele contém de ponta a ponta, mas em que do mesmo modo se acha preso.

Nesse sentido, o pensamento seria concebido a partir do efeito de articulação das redes de saberes e poderes que, materializadas na cultura, produzem e conduzem formas de vida qualificadas como virtuosas. 0 pensamento não seria manifestação da interioridade, ao contrário, seria uma força advinda do que está do lado de fora, promovendo inter-relações. O autor ainda sinaliza que o cotidiano escolar e o pensar educacional deveriam se habitar de um desassossego na linguagem, assumindo 0 trabalho do pensamento como gesto de divergência afirmativa em busca de criação, recusando a reflexividade dócil rumo à compreensão.

A escola hoje tem uma função maior. Ela precisa deixar de cumprir o papel de maquinaria de produção de verdades educacionais e passar a ensinar o aluno a refletir em face do mundo diverso, a produzir conhecimento, a acreditar que a educação está para além dos conteúdos, até porque, segundo Senna (2008, p.215) "a escola há muito deixou de ser a fonte mais confiável de saber [...] Os saberes que povoam a escola hoje tornaram-se circunstanciais".

Dentro dessa perspectiva é importante refletirmos sobre o conceito de escola com o qual convivemos e se, é nele que acreditamos. A falta de identidade das nossas instituições faz com que elas não tenham um projeto de ensino consubstanciado que possa ser compartilhado por todos. Tendo em vista essa situação, fazer com que nossos professores sejam capazes de vislumbrar uma concepção de ensino para além do conteúdo é tarefa complexa. Alguns profissionais não são capazes de sequer explicar para eles próprios a serventia do conteúdo ministrado, contudo continuam propagando a ideia de que a maior função do professor é essa. Ensinar a partir de pacotes conteudistas é fazer parte desses pacotes, mas se compreendermos que nosso papel como educadores tem outro valo: conseguiremos nos transformar e, transformar nossos alunos em sujeitos 
intelectuais. O desenvolvimento intelectual é imprescindível no processo educacional, caso contrário, a figura do professor será ilegítima.

A urgência de uma construção identitária para uma escola para o século XXI passa ser um dos grandes desafios dos profissionais de educação no Brasil. A necessidade de reverter a imagem de uma instituição que é fonte do saber e se constitui por sujeitos homogêneos, faz com que tenhamos de repensar perspectivas para uma educação inclusiva que privilegie demandas reais e deem condições de trabalho aos profissionais que nelas atuam.

Morin (1999, p.29) faz alusão à teoria dos autônomos autoreprodutores, postulada por Von Neuman'11 (1956), para discutir sobre a importância da busca do conhecimento numa sociedade complexa.

\begin{abstract}
A teoria dos autônomos auto-reprodutores postulou a seguinte questão: por que será que as máquinas artificiais que construímos com materiais extremamente confiáveis (...) são menos confiáveis em seu futuro que as máquinas naturais - os seres vivos -, que são construídos com materiais muito pouco confiáveis (...)? E a resposta só pode ser que a máquina artificial não tem poder de se autoreparar, de se auto-transformar e mesmo de se auto-reproduzir.
\end{abstract}

A analogia proposta pelo autor nos faz compreender que somos dotados da capacidade de nos alimentar da desordem para nos regenerar, de reformular nossos pensamentos com o propósito de auto-organização e de reflexão. Que conceber o conhecimento a partir de experiências é necessário, e que para isso, precisamos reconhecer a complexidade como uma forma de inteligência.

Nesse sentido, é viável que passemos a reconhecer a escola não como um ser onipotente, capaz de afirmar a existência de uma realidade divina, independente das questões que se encontram em torno dela. Mas

\footnotetext{
111 O trabalho refere-se à síntese de organismos confiáveis publicado pela primeira vez em 1956, lançando os fundamentos da teoria de confiabilidade e tolerância a falhas que continuou atraindo muito interesse e contribuições de pesquisadores.
}

Revista Exitus, Santarém/PA, Vol. 7, № 1, p. 269-288, Jan/Abr 2017. 
deveríamos pensá-la como uma figura capaz reger a realidade objetiva ${ }^{112}$, propondo dúvidas como forma de articular e o pensamento.

Para incitarmos essa reflexão sobre o papel da escola e do professor na produção do conhecimento, abordaremos algumas questões que tratarão sobre as relações sociais e políticas que sustentam nossas instituições de ensino nos dias atuais. Será que é verdade que nossas disciplinas escolares formam pessoas cognitivamente? Os cursos de formação profissional estarão de acordo com a realidade educacional? Como o professor pode dispor sobre o ensino se ele não aprendeu a constituir uma outra forma de ensinar?

\section{EDUCAR PARA PENSAR}

A ideia de universalização do acesso à escola, questão já apresentada no iluminismo, nunca deixou de ser pauta de discussão entre pessoas que pensam na educação. No entanto, na pós-modernidade, essa questão vem ganhando uma conotação (particularmente na rede pública), a qual distancia-se de um dos principais objetivos da escola - promover à formação cultural e científica através do desenvolvimento das capacidades intelectuais.

Segundo Libâneo (2012, p.14) "não há justiça social sem conhecimento; não há cidadania se os alunos não aprenderem". Dessa forma, é inegável pensar a ideia de universalização desassociada do conhecimento, possibilidade a substituição do mesmo por ações de acolhimento que acabam gerando insucesso e fracasso naqueles que de alguma forma já foram excluídos do sistema. É notório o dever da escola com tarefas assistenciais, afinal ela convive com diferenças sociais graves e não pode se negar a enxergá-las.

Para Nóvoa (2009) um dos embates dos tempos atuais é pensar numa escola a "duas velocidades".

112 Descartes concebia a realidade objetiva como um conteúdo de ideias efetivas e atuais, as quais faziam parte de uma realidade formal. 
Um dos grandes perigos dos tempos atuais é uma escola a "duas velocidades": por um lado, uma escola concebida essencialmente como um centro de acolhimento social, para os pobres, com uma forte retórica da cidadania e da participação. Por outro lado, uma escola claramente centrada na aprendizagem e nas tecnologias, destinada a formar os filhos dos ricos (p.64).

A necessidade de se discutir acordos políticos-educacionais que revejam essa questão e que, reestruturem ações pedagógicas para 0 princípio da universalidade, se faz presente, tendo em vista que as pessoas não enxergam com nitidez a função real da escola, e por isso, ora optam pelo acesso sem as devidas responsabilidades, ora pela transmissão de conteúdos com o propósito de aprovações em vestibulares. Contrariando essa realidade, as políticas deveriam propiciar ao aluno além da universalização ao acesso, permanência nas instituições de ensino, propondo qualidade na educação, atendimento às diferenças sociais e culturais e a formação para a cidadania.

Estamos inseridos em um contexto educacional que teve como avanço absorver minorias sociais, todavia, é preciso reconhecê-los como alunos e para isso é indispensável pensar no processo pautado na qualidade de ensino. Caso isso não aconteça, é provável que essa inclusão se converta em roleta russa. Entende-se que essa situação é verdadeiro paradoxo, pois a educação até hoje não conseguiu promover atos que mantenham na escola pessoas em condições de igualdade. Os estudos a esse respeito não estão e nunca tiveram alicerçados em teorias epistemológicas sólidas, se fazendo na maioria por experimentos, por hipóteses, não se constituindo por um corpo teórico consistente que diga que esse experimento não é uma caridade. E é também por essa razão que os professores às vezes se sentem angustiados.

Em decorrência dessa instabilidade que se instala no cotidiano da escola, precisamos suspeitar de ações que não promovem resultados satisfatórios que façam sustentar antigas práticas. Estamos impregnados de discursos que dizem que temos a necessidade de absorver minorias sociais, que devemos reconhecer nossos alunos como sujeitos, mas que não 
conseguimos fazê-lo, apesar de possuirmos algum amparo das políticas públicas. E então, o que será que ainda nos falta? Responder a essa pergunta, com tranquilidade, seria desprezar a Teoria de Berticelli (2004), a qual nos aponta que:

A educação é, acima de tudo, comunicação entre os seres educáveis, interação, auto-hetero-organização complexa, uma ação/atividade que, como todo processo cognitivo, comporta sombras, zonas cegas, buracos negros, caos (p.488).

Discutir essas questões é ter que abrir espaço para o professor "sentarse à mesa", conforme declara o autor, para rever os contratos sociais que foram firmados ao longo do tempo na área da Educação. É querer enxergar que a escola muda de significação nos vários tempos e espaços sociais e que, precisamos ter convicção de que necessitamos, com urgência, vivenciar abordagens transversais, abrir diálogos entre diferentes tendências e teorias que contribuam para nossa formação. É entender que precisamos reformular o pensamento dos profissionais envolvidos com o processo ensinoaprendizagem.

Para integrar-se a essa realidade e ajudar a promover a universalidade e permanência dos sujeitos em nossas escolas, o professor necessita de uma formação que discuta questões sobre condições para o desenvolvimento cognitivo, afetivo e moral dos alunos. Caso contrário, a aprendizagem poderá se transformar numa visão instrumental, desprovida de caráter cognitivo, desvinculada do acesso e formas superiores de pensamento (LIBÂNEO, 2012).

O professor necessita de alguns requisitos para conduzir esse processo, que a cada dia tem se tornado mais complexo. Becker (1993), Tardif (2002), Senna (2008) e Libâneo (2013) endossam essa questão quando nos induzem a reflexões sobre o papel do professor como um sujeito que dá significados às práticas educacionais. Para eles o professor é o agente da escola, aquele que precisa ser um pesquisador de sua própria prática e 
quem deve saber o que fazer e, por essa importância, deve enfrentar as mudanças se apropriando simultaneamente do saber prático e teórico.

Segundo Senna (2008), os objetivos e as funções da escola já não são as mesmas do século XVIII. O autor aponta que o ensino através de uma metodologia acrítica se mostra inadequado para os dias de hoje, mas também questiona qual função do educador nessa mudança de paradigma. "Se hoje o professor não mais é formado para reproduzir metodologias inócuas, como ele passou a se organizar para ensinar aquilo que ainda é sua obrigação ensinar como agente de educação básica?" (p.214). O autor ainda argumenta que a realidade de nossas escolas nos induz a acreditar que a falta de resposta para tal questionamento fez com que o professor tenha se tornado uma pessoa extremamente consciente e crítico de seu papel social, porém, algumas vezes despreparado para intervir na qualidade de agente de educação formal do ensino básico.

Becker (1993) colabora com essa questão, quando ressalta a importância de o professor associar sua prática às teorias bem fundadas epistemologicamente, a fim de que ele possa articular novas ideias e não negar sem conseguir reestruturá-las.

Muitos professores, mergulhados na sua prática docente, emergem dela insatisfeitos, esbravejam contra ela, dizem palavrões, ironizam, chegam, às vezes, ao sarcasmo. Mas não conseguem reestruturá-las em nível de seu desejo, de sua vontade política. Por quê? Nossa hipótese é que Ihes falta, fundamentalmente a teoria capaz de resignificar sua prática, e, a partir dessa re-significação, re-estruturá-la (p.161).

Sabemos que o professor lida com um plural de coisas que convivem complexamente com o mundo real. Que cada aluno é uma realidade diferente e que, por vezes, exige dele uma posição de questionamento.

Para corroborar com a posição dos autores acima, é pertinente trazer a fala de Piaget (1973, p.85) que endossa a postura do professor em sua prática educativa: "pensar é agir sobre o objeto e transformá-lo". Com esse pensamento, observa-se que as características apontadas pelo autor se 
afinam às do professor, um ser essencialmente ativo e reflexivo, que por vezes, adota uma postura quase de inconsciência epistêmica diante de sua prática.

Muitas vezes essas práticas pedagógicas que ocorrem de maneira inconsciente são as verdadeiras responsáveis por produzir políticas dentro das escolas, o que nos mostra o quanto o docente tem procurado resolver os problemas educativos partindo dos saberes práticos que ele adquire. Essa abordagem sugere que é viável repensar sobre o que os profissionais da educação aprendem nos cursos de formação acadêmica e o que se pratica no cotidiano da escola, para que assim consigam transitar entre 0 conhecimento teórico e o prático, já que em princípio, deveriam ser indissociáveis para o desenvolvimento profissional de qualidade.

A relação teoria-prática é defendida por Libâneo (2013), ao afirmar que:

De fato, não é verdade que basta uma boa teoria para que um profissional tenha êxito na prática. Mas, também, não é verdade que a prática se basta por si mesma. Nem toda prática pode ser justificada como adequada, assim como não é possível qualquer reflexão sobre a prática se não há da parte do professor um domínio sólido dos saberes profissionais, incluída aí uma boa cultura geral (p.38).

Para Mantoan (2008, p.83) existe uma disparidade entre a formação do professor e sua atuação. De acordo com a autora, levar a universidade a considerar esse distanciamento é complexo, pois "pensar nas diferenças em sala de aula é uma coisa muito difícil, porque o aluno continua a ser, para a universidade, aquele ser ideal, que é fruto do que a teoria nos mostrou a respeito dos seres humanos".

Parece claro que a superação da dicotomia ação-reflexão permitirá ao professor ser agente da prática educativa, evitando assim utilizar apriorismos (BECKER, 1993), ainda mais no contexto "Brasil" - um país cuja complexidade está intrínseca em nossas características. Porém, essa mudança não se faz da noite para o dia, muito menos num passe de 
mágica, e por isso exige que todas as esferas políticas-educacionais voltem seus olhares para essa realidade presente em nossas escolas.

\section{ENTRE A REALIDADE E A POSSIBILIDADE DE UMA AÇÃO PEDAGÓGICA QUE SUSTENTE A PRÁTICA ESCOLAR}

Doutrinar, preservar valores de uma determinada camada da sociedade, moldar o homem desprovido de uma educação familiar, formar o operariado e prepará-lo para o mercado de trabalho foram algumas das questões fundamentais para que as pessoas enxergassem a escola como algo indispensável à sociedade durante nossa história. Evidenciando que, ainda é esta a imagem com a qual trabalhamos até os dias atuais - uma escola pública, concebida como espaço de integração social, que visa construir um homem para sociedade.

Nos últimos anos, os discursos sobre as funções da escola manifestaram-se, de forma reiterada, na pauta da educação. Libâneo (2013) aponta alguns dos motivos pelo qual ela se tornou preocupação de órgãos internacionais.

O fato de ela ser tradicional, estar baseada no conteúdo, ser autoritária e, com isso, constituir-se como uma escola que reprova, exclui os mal-sucedidos, discrimina os pobres, leva ao abandono da escola e à resistência violenta dos alunos. Tal como aparece nos documentos dos organismos internacionais, é preciso um novo modelo de escola, novas práticas de funcionamento (p.19).

Entretanto esse novo modelo de escola é proposto à sociedade através de Kits pedagógicos. Para o autor (ibidem), há na escola hoje um transbordamento de objetivos, fazendo com que ela assuma as seguintes características:

a) conteúdos de aprendizagem entendidos como competências e habilidades mínimas para a sobrevivência e o trabalho (como um kit de habilidades para a vida); b) avaliação do rendimento escolar por meio de indicadores de caráter quantitativo, ou seja, independentemente de processos de aprendizagem e formas de aprender; c) aprendizagem de valores e atitudes requeridos pela nova cidadania (ênfase na sociabilidade pela vivência de ideais de solidariedade e participação no cotidiano escolar) (p.20). 
Esses mesmos Kits chegam até às mãos do professor, como proposta inovadora de produção de conhecimento. As novas políticas educacionais oferecem a ele um pacote de sobrevivência docente (laboratórios de informática, técnicas para uso de livro didático, formação pela EaD), como se esses recursos fossem suficientes para produzir um professor reflexivo diante de sua prática. Importante destacar que todos esses mecanismos contribuem, mas não são fatores essenciais que devem assumir a linha de frente na educação.

Há razões para crer que esse modelo de educação não está funcionando. Poderíamos afirmar que resultados do Programa Internacional de Avaliação de Estudantes (Pisa), em que o Brasil ainda está nas posições mais baixas do ranking, seriam suficientes para validar essa posição, porém, trazer questões mais próximas do nosso dia a dia, como: a descrença do professor no processo de ensino, evasão escolar, índice que docentes que se afastam por doenças psicológicas, carência estrutural de nossas instituições, falta de diálogo entre a universidade e escolas, carência de profissionais habilitados, enfim, pelo fracasso do nosso ensino público; faz com que vejamos esse problema bem mais perto de nós.

Para Senna (1997) a solução do problema da escola pública brasileira passa necessariamente por dois fatores:

i) o reconhecimento de que ainda falta à Escola legitimar seu caráter nacional, o que implica reconhecer o perfil plural e nãoeuropeu da sociedade brasileira, e ii) a reavaliação daquilo que formalmente se tem considerado como "conteúdo programático escolar", de maneira que a Escola seja verdadeiramente capaz de instrumentalizar o aluno para interagir com 0 mundo atual e, consequentemente, seja capaz e se mostrar atrativa e motivadora para o processo de aprendizagem (p.14).

O autor ainda pontua que para promover o desenvolvimento pleno do aluno, a escola deve pensar nele como um ser com características inerentes a tudo aquilo que o faz ser uma pessoa, e não, um outro ser qualquer. E para isso, ela deve ter como proposta vários aspectos relacionados ao desenvolvimento. 
i) físicos: [...] Além de compreender os diferentes estágios de transformações físicas dos alunos, a Escola deverá, igualmente, promover experiência que os auxiliem a desenvolver satisfatoriamente seu corpo e seu sistema cognitivo. ii) Aspectos emocionais: [...] Um dos papeis mais importantes - e quase sempre mais desprezado - da Escola é o de ajudar o aluno a desenvolver a compreensão de suas emoções, neste período de constante autodescoberta que a idade escolar. iii) Aspectos sociais: [...] 0 desenvolvimento do comportamento social do aluno é uma tarefa primordial da Escola, tendo em vista que, para a criança e o jovem, o ambiente escolar é, de fato, o primeiro e mais imediato laboratório de suas relações com o mundo exterior. iv) Aspectos cognitivos e intelectuais: Cabe à escola desenvolver a inteligência do aluno e ampliar sua capacidade de conhecer coisas novas (p.17).

Para os dois autores, "conhecimento" e "cidadania" são termos concatenados. Compreende-se que não há justiça social sem conhecimento e não há cidadania se os alunos não aprendem. Que todos os alunos têm direito a uma base comum de conhecimento, para que possam usar de maneira eficaz em suas vidas. Também cabe à escola se apropriar de ações que contenham o insucesso e o fracasso escolar desse sujeito aprendente. Desse modo, a articulação dessas conjunções, implicará em transformações substantivas no modo de desenvolvimento a ser articulado no processo educacional.

\section{ALGUMAS CONSIDERAÇÕES}

A universalização do ensino e o poder delegado às escolas não são políticas contemporâneas, tendo em vista que os ideais iluministas já apontavam essas questões como forma de transformação do homem natural em homem civil, sem degradá-lo. E para que isso se tornasse viável, caberia confiar esse homem às boas instituições e ao poder da educação.

Entende-se que esse legado muito contribuiu para o modelo de ensino que temos na atualidade e para a manutenção da ideia de que a escola é a maior responsável por tornar alguém capaz de conviver em sociedade. Todavia, cabem reflexões a respeito do tipo de universalização que se promovido em nosso país. Pensar nessa universalização é entender que não basta abrir os portões da escola sem assumir responsabilidades. 
A crença e a confiabilidade que se depositou nessa instituição, precisam ser resgatadas se quisermos verdadeiramente incluir. Receber matrículas não é sinônimo de inclusão, e sim uma das propriedades que compõem esse processo. Inclui-se a partir do momento em que há desenvolvimento do aluno em todos os sentidos expressos pela palavra.

Assegurar uma ação educativa dentro de nossas escolas que faculte aos nossos sujeitos aprendentes a condição de cidadão é ter em mente que cabe a ele 0 direito de se promover intelectualmente, através de conhecimentos culturais e científicos que levem em conta suas particularidades sociais e econômicas. Se o excluirmos dessa condição, jamais nosso aluno incluído será tratado com equidade.

Observa-se que o modelo de ensino oferecido em nossas escolas deixa de levar em conta particularidades do sujeito pós-moderno - um indivíduo eclético, aberto a novas possibilidades de aprendizagem e que possui uma mescla de saberes adquiridos em outros espaços. Também, esse mesmo modelo perpetua a crença de que se deva ensinar de maneira igual a todos, caso contrário, estaria descumprindo a noção de isonomia. Tendo em vista essa realidade, é fato que a escola precisa pensar sobre sua função dentro desse contexto diverso.

Cabe também ao professor ser um agente atuante no processo ensino-aprendizagem, apropriando-se da trilogia 'querer- aprender- fazer' para que assim possa deixar de pertencer a um sistema engessado, cujas metodologias de ensino não se norteiam pelo processo do ensinar a pensar.

Enfim, após toda discussão ao longo do texto em que se procurou evidenciar que o processo de universalização escolar só se efetivará mediante reflexões que envolvam todas as instâncias de ensino; apropriação do professor sobre sua real função no processo educativo e, valorização da educação por parte do Estado; resta-nos reiterar que, a escola é um espaço fértil para a democratização social e promoção da inclusão social, uma vez que não deixe de ofertar sua tarefa básica: a atividade de aprendizagem dos alunos. 


\section{REFERÊNCIAS}

ARANHA, M. S. F. Educação inclusiva: transformação social ou retórica? In: OMOTE, S. Inclusão: intenção e realidade. Marília, SP: Fundepe Publicações, 2004.

BECKER, F. A Epistemologia do Professor: o cotidiano da escola. Petrópolis, RJ: Vozes, 1993.

BERTICELLI, I. A. A origem normativa da prática educacional na linguagem. ljuí: Ed.Inijuí, 2004.

BOTO, C. A escola do homem novo: entre o lluminismo e a Revolução Francesa. São Paulo: Editora da Universidade Paulista, 1996.

CALÇA, R. P. Duas escolas, duas expressões do iluminismo - Rousseau e Condorcet: $O$ futuro que o passado ousou projetar. Tese de doutorado (Faculdade de Educação). Universidade de São Paulo, 2010.

FOUCAULT, M. As palavras e as coisas: uma arqueologia das ciências humanas. 8. ed. São Paulo: Martins Fontes, 1999.

LIBÂNEO, J. C. Organização e gestão da escola: teoria prática. 6.ed. São Paulo: Heccus Editora, 2013.

LIBÂNEO, J. C. J. C. O dualismo perverso da escola pública brasileira: escola do conhecimento para os ricos, escola do acolhimento social para os pobres. Educação e Pesquisa. São Paulo, v. 38, n. 1, p. 13-28, 2012.

MANTOAN, M. T. E. Ultrapassar Barreiras e Avançar na Inclusão Escolar. In: Avanços e desafios na construção de uma sociedade inclusiva. Rosa Maria Corrêa (Org) - Belo Horizonte: Sociedade Inclusiva/PUC-MG, 2008.

MORIN, E. O Método 3. O Conhecimento do conhecimento. Porto Alegre: Sulina, 1999.

RIBEIRO, C. R. "Pensamento do fora", conhecimento e pensamento em educação: conversações com Michel Foucault. Educação e Pesquisa. São Paulo, v.37, n.3, p. 613 - 628, set./nov. 2011.

NÓVOA, A. Professores: imagens do futuro presente. Lisboa: Educa, 2009

PIAGET, J. Para onde vai a educação? Rio de Janeiro: Editora Unesco, 1973.

SENNA, L. A. G. O currículo na Escola Básica: caminhos para a formação da cidadania. Rio de Janeiro: Qualitymark/Dunya Ed.1997.

SENNA, L. A. G. Formação Docente e Educação Inclusiva. Cadernos de Pesquisa. vol.38 no. 133. São Paulo. Jan/abril 2008.

SEVERINO, E. A filosofia Moderna. Edições 70. Tradução: de José Eduardo Rodil. São Paulo: Editora Martins Fontes, 1984.

TARDIF, M. Saberes docentes e formação profissional. Petrópolis: Vozes, 2002.

UNESCO. Representação da Unesco no Brasil. 2015. Disponível em: < http://www.unesco.org/new/pt/brasilia/education/education-for-all/>. Acesso em 25 de set. 2015. 
VON NEUMANN, J. Probabilistic logics and the synthesis of reliable organisms from unreliable components. Em Taub (1963), p. 329-378, 1956.

Recebido em: Junho de 2016 Aceito em: Setembro de 2016 